\title{
Avaliação do Dano Oxidativo ao DNA de Células Normais e Neoplásicas da Mucosa Cólica de Doentes com Câncer Colorretal
}

\author{
Evaluation of Dna Oxidative Damage in Normal and Neoplastic Cells \\ of Colonic Mucosa in Patients With Colorectal Cancer
}

\author{
MARCELO LIMA RIBEIRO ${ }^{1}$, DENISE GONÇALVES PRIOLLI², DANIEL DUARTE DACONCEIÇÃO MIRANDA, \\ DEMÉTRIUS ARÇARI PAIVA ${ }^{3}$, JOSÉ PEDRAZZOLI JÚNIOR ${ }^{1}$, CARLOS AUGUSTO REALMARTINEZ ${ }^{2}$
}

\begin{abstract}
1. Professor Assistente Doutor do Programa de Pós-graduação em Ciências da Saúde da Universidade São Francisco, Bragança Paulista (SP); ${ }^{2}$ Professor Adjunto Doutor do Curso de Medicina da Universidade São Francisco, Bragança Paulista (SP); ${ }^{3}$ Acadêmico do Curso de Medicina da Universidade São Francisco, Bragança Paulista, (SP); ${ }^{4}$ Mestrando do Curso de Pós-graduação em Nutrição da Faculdade de Saúde Pública da Universidade de São Paulo, (SP); ${ }^{5}$ Professor Livre-Docente e Coordenador do Programa de Pós-graduação em Ciências da Saúde da Universidade São Francisco, Bragança Paulista, (SP); ${ }^{6}$ Professor Adjunto Doutor do Programa de Pós-graduação em Ciências da Saúde da Universidade São Francisco, Bragança Paulista, (SP).
\end{abstract}

RIBEIRO ML; PRIOLLI DG; MIRANDA DDC; PAIVA DA; PEDRAZZOLI JÚNIOR J; MARTINEZ CAR. Avaliação do Dano Oxidativo ao DNA de Células Normais e Neoplásicas da Mucosa Cólica de Doentes com Câncer Colorretal. Rev bras Coloproct, 2007;27(4): 391-402.

RESUMO: O estresse oxidativo ao DNA de células da mucosa cólica decorrente de radicais livres de oxigênio presentes na luz intestinal, induz mutações de genes relacionados ao controle do ciclo celular, representando um dos fenômenos iniciais da carcinogênese colorretal. A quantificação do dano oxidativo ao DNA em portadores de câncer colorretal foi pouco estudada até o momento. Objetivo: O objetivo do presente estudo foi mensurar os níveis de dano oxidativo ao DNA de células isoladas da mucosa cólica de doentes com câncer colorretal comparando o tecido normal e o neoplásico e correlacionando-os a variáveis anatomopatológicas. Método: Estudou-se 32 enfermos (19 mulheres) com média de idade de 60,6 \pm 15,5 anos, portadores de adenocarcinoma colorretal operados consecutivamente, entre 2005 e 2006 . A avaliação do dano oxidativo ao DNA foi realizada pela da versão alcalina do ensaio cometa (eletroforese e gel de célula única), a partir de fragmentos de tecido cólico normal e neoplásico obtidos imediatamente após a extirpação do espécime cirúrgico. Avaliou-se a extensão das rupturas das hélices do DNA com método de intensificação de imagem, em 200 células escolhidas aleatoriamente (100 de cada amostra de tecido) com o programa Komet 5.5. A mensuração da cauda obtida de cada célula (Tail Moment) representava, quantitativamente, a extensão do dano oxidativo ao DNA. A análise estatística das variáveis consideradas foi realizada pelos testes t de Student, qui-quadrado e Kruskal-Wallis, adotando-se nível de significância de $5 \%(p<0,05)$. Resultados: Verificou-se em todos os doentes que as células obtidas do tecido neoplásico apresentavam maior intensidade de dano oxidativo ao DNA do que as células oriundas do tecido normal. As células isoladas da mucosa cólica neoplásica apresentavam, em média, extensão de ruptura das hélices do DNA (T.M. $=2,532 \pm 0,945)$ significativamente maior quando comparadas às células isoladas do tecido normal $($ T.M. $=1,056 \pm 0,460)$ (p=0,00001; I.C.95\%: -1,7705 -1.1808). Verificou-se que os doentes pertencentes aos estádios mais precoces da classificação de Dukes e TNM apresentavam maiores níveis de dano oxidativo do que os pertencentes a estádios mais avançados (p=0,04 e p=0,001 respectivamente).Conclusões: As células obtidas do tecido normal de portadores de câncer colorretal apresentam sinais de danos oxidativos ao DNA celular, embora significativamente menores que as células neoplásicas.

Descritores: Estresse Oxidativo. Oxidantes. Ensaio em Cometa. Neoplasias Colorretais.

Trabalho realizado no Programa de Pós-Graduação em Ciências da Saúde da Universidade São Francisco, Bragança Paulista, São Paulo.

Recebido em 06/09/2007

Aceito para publicação em 23/10/2007 


\section{INTRODUÇÃO}

O câncer colorretal (CCR) representa uma das principais causas de morte por neoplasia em todo mundo. ${ }^{1,2}$ Não obstante os recentes avanços obtidos no diagnóstico precoce e tratamento, os índices de mortalidade pouco se alteraram ${ }^{3}$. No Brasil, a evolução do CCR tem apresentado comportamento semelhante sendo, atualmente, a quinta causa mais comum de morte relacionada ao câncer. ${ }^{4} \mathrm{~A}$ exemplo do que acontece em outros países, a incidência do CCR vem aumentando em comparação a outros tipos de tumores que acometem o aparelho digestivo. ${ }^{4,5} \mathrm{O}$ aumento da expectativa de vida, os fenômenos da globalização e, principalmente, a mudança de hábitos dietéticos fizeram com que o CCR ganhasse importância crescente no perfil da mortalidade por câncer em todo o mundo. ${ }^{6}$

Desde a publicação do trabalho pioneiro de Fearon e Vogelstein em 19907, encontra-se bem estabelecido que o surgimento do CCR, a partir da mucosa cólica inicialmente normal, é mediado por uma seqüência de mutações em genes controladores do ciclo celular (proliferação, diferenciação, adesão e apoptose). A partir de então, o grande desenvolvimento da biologia molecular vem permitindo a melhor compreensão dos mecanismos genéticos e moleculares envolvidos no desenvolvimento do CCR. ${ }^{7}$ Contudo, o evento inicial responsável pela transformação da célula normal da mucosa cólica em célula neoplásica ainda não se encontra totalmente esclarecido. Alguns estudos demonstraram que a hipermetilação da região promotora de genes bloqueando sua transcrição e o dano oxidativo ao DNA nuclear (estresse oxidativo), talvez representem dois dos principais mecanismos relacionados às etapas iniciais da carcinogênese colorretal. ${ }^{8,9}$

$\mathrm{O}$ desenvolvimento do CCR encontra-se fortemente associado a hábitos alimentares. Estudos epidemiológicos indicam que o consumo de carne vermelha, gordura e álcool aumentam significativamente o risco da doença, enquanto a ingestão regular de vegetais e fibras parece diminuir este risco. ${ }^{10,11,12,13} \mathrm{O}$ consumo de carne vermelha por elevar consideravelmente a concentração do íon ferro no lúmen intestinal, determina aumento nos níveis de espécies reativas de oxigênio (ERO). ${ }^{14,15} \mathrm{O}$ aumento na formação das ERO na luz intestinal e a exposição contínua da mucosa a estes radicais livres geram danos oxidativos ao ácido desoxirribonucléico (DNA) das células epiteliais, desencadeando o aparecimento de mutações genéticas. ${ }^{16}$
Quando essas mutações comprometem genes responsáveis pelo controle do ciclo celular, podem surgir clones de células com autonomia proliferativa, representando o mecanismo inicial da carcinogênese colorretal.

É sabido que a agressão crônica à mucosa cólica promovida pelas ERO, provoca o aparecimento de processo inflamatório crônico que, alterando progressivamente a arquitetura normal do epitélio cólico, promove o surgimento de áreas com graus crescentes de displasia tecidual, e alteração histológica precursora do CCR. ${ }^{17}$ Algumas evidências reforçam essas suposições merecendo destaque, à estreita relação existente entre as doenças inflamatórias intestinais crônicas, representadas pela colite ulcerativa e enfermidade de Crohn, e o CCR. ${ }^{17}$ Nos doentes portadores dessas enfermidades, quanto mais intensa e duradoura for à agressão oxidativa ao epitélio mucoso do cólon, maior será o risco do surgimento da neoplasia. ${ }^{17}$

Até o momento, a mensuração dos níveis de estresse oxidativo ao DNA envolvia técnicas bioquímicas sofisticadas que necessitavam de considerável quantidade de tecido para a sua correta quantificação. Dessa forma, em virtude dos limites relacionados com a obtenção de material suficiente para análise, essas técnicas não podiam ser aplicadas em pequenas quantidades de tecidos, como aqueles obtidos durante procedimentos endoscópicos. Por esta razão, encontram-se poucos estudos que quantificaram o dano oxidativo ao DNA em portadores de CCR comparando os tecidos normais e neoplásicos. ${ }^{18}$ Com o advento da técnica da eletroforese em gel de célula única (ensaio do cometa) é possível quantificar-se os níveis de danos oxidativos ao DNA em uma célula isolada. $\mathrm{O}$ ensaio do cometa permite a medida dos níveis de estresse oxidativo em pequenos fragmentos de tecido, possibilitando o estudo comparativo entre células normais e neoplásicas da mucosa cólica nos diversos estágios do desenvolvimento do CCR. ${ }^{18}$ Esta possibilidade torna o método atraente na quantificação do nível de dano oxidativo comparando tecido normal, pólipos com diversos graus de displasia e tecido neoplásico. A possibilidade de quantificar o dano oxidativo em pequenos fragmentos teciduais permite ainda avaliar a eficácia de agentes antioxidantes, tais como os inibidores de COX-2, na prevenção da agressão oxidativa ao DNA celular nas diversas etapas da seqüência adenoma-carcinoma.

Diante dessas evidências é de fundamental importância compreender o papel das ERO no dano oxidativo ao DNA das células da mucosa cólica. As- 
sim sendo, objetivo do presente estudo foi quantificar e comparar os níveis de estresse oxidativo ao DNA das células normais e neoplásicas isoladas da mucosa do intestino grosso de doentes portadores de CCR.

\section{MÉTODO}

A realização do presente estudo recebeu aprovação do Comitê de Ética em Pesquisa da Universidade São Francisco tendo todos pacientes, assinado Termo de Consentimento Livre e Esclarecido após serem informados de todas as etapas da pesquisa.

\section{Casuística:}

Foram estudados de modo prospectivo, 32 enfermos (19 mulheres), com média de idade de 60,6 \pm 15,5 anos, portadores de adenocarcinoma do cólon e reto, operados com intenção curativa por uma mesma equipe cirúrgica, entre julho de 2005 e abril de 2007. Foram excluídos os doentes com CCR hereditário (polipose adenomatosa familiar e câncer colorretal hereditário não polipóide), portadores de CCR associado à doença inflamatória intestinal e, aqueles submetidos a tratamento radioterápico ou quimioterápico neoadjuvante. Os enfermos selecionados para o estudo foram submetidos ao estadiamento clínico, laboratorial e por exames de imagem segundo as diretrizes recomendadas pela Associação Médica Brasileira. ${ }^{19}$

As características clínicas e anatomopatológicas dos doentes encontram-se relacionadas na Tabela 1.

\section{Coleta do Material}

Imediatamente após a extirpação do espécime cirúrgico foram retirados três fragmentos de tecido normal da margem proximal de ressecção cirúrgica. Da mesma forma, foram colhidos três fragmentos de tecido neoplásico obtidos da periferia do tumor. Os fragmentos obtidos foram acondicionados em recipiente apropriado, e imediatamente enviados ao Laboratório de Biologia Molecular onde eram resfriados a $-80^{\circ} \mathrm{C}$, até o momento da realização do ensaio do cometa.

\section{Exame Anátomo-Patológico}

$\mathrm{O}$ estudo macroscópico dos espécimes extirpados analisou a localização do tumor, o tamanho e tipo de crescimento. Na realização do estudo histopatológico, todos os espécimes cirúrgicos previa-
Tabela 1 - Características clínicas $e$ histopatológicas da casuística estudada.

\begin{tabular}{|c|c|c|}
\hline \multirow{2}{*}{$\begin{array}{l}\text { Variáveis } \\
\text { Sexo }\end{array}$} & \multicolumn{2}{|c|}{ Porcentagem (n) } \\
\hline & & \\
\hline Homem & 46,9 & $(15 / 32)$ \\
\hline Mulher & 53,1 & $(17 / 32)$ \\
\hline \multicolumn{3}{|l|}{ Idade } \\
\hline$<70$ anos & 71,9 & $(23 / 32 \mid)$ \\
\hline$>70$ anos & 28,1 & $(9 / 32)$ \\
\hline \multicolumn{3}{|l|}{ Topografia } \\
\hline Cólon Proximal & 12,5 & $(4 / 32)$ \\
\hline Cólon Distal & 87,5 & $(28 / 32)$ \\
\hline \multicolumn{3}{|l|}{ Grau histológico } \\
\hline Bem & 9,4 & $(3 / 32)$ \\
\hline Moderadamente & 84,4 & $(27 / 32)$ \\
\hline Pouco & 6,3 & $(2 / 32)$ \\
\hline \multicolumn{3}{|l|}{ Tipo histológico } \\
\hline Não mucinoso & 75,0 & $(24 / 32)$ \\
\hline Mucinoso & 25,0 & $(8 / 32)$ \\
\hline \multicolumn{3}{|c|}{ Classificação TNM } \\
\hline I & 9,4 & $(3 / 32)$ \\
\hline II & 31,3 & $(10 / 32)$ \\
\hline III & 31,3 & $(10 / 32)$ \\
\hline IV & 28,1 & $(9 / 32)$ \\
\hline \multicolumn{3}{|c|}{ Classificação de Dukes } \\
\hline A & 9,4 & $(3 / 32)$ \\
\hline B & 40,6 & $(13 / 32)$ \\
\hline $\mathrm{C}$ & 50,0 & $(16 / 32)$ \\
\hline \multicolumn{3}{|c|}{ Invasão angiolinfática } \\
\hline Presente & 50,0 & $(16 / 32)$ \\
\hline Ausente & 50,0 & $(16 / 32)$ \\
\hline \multicolumn{3}{|l|}{ Invasão neural } \\
\hline Presente & 40,6 & $(13 / 32)$ \\
\hline Ausente & 59,4 & $(13 / 32)$ \\
\hline
\end{tabular}

mente fixados em solução de formol a $10 \%$, foram emblocados em parafina. Foram obtidos de cada bloco seis cortes de $4 \mathrm{~mm}$, sendo três da margem proximal de ressecção, e três outros da periferia do tumor para obtenção de tecido com e sem neoplasia, sendo corados pela técnica da hematoxilina-eosina para diagnóstico microscópico e avaliação do nível de invasão na parede intestinal, tipo histológico, grau de diferenciação celular, presença de invasão angiolinfática ou neural e número de linfonodos comprometidos. O estadiamento dos doentes foi feito segundo as classificações de Dukes e TNM. 


\section{Ensaio do Cometa}

Para a realização do ensaio do cometa foram utilizados: um fragmento obtido do tecido neoplásico e um fragmento de tecido normal. A análise do dano oxidativo ao DNA das células da mucosa cólica foi feita de acordo com método anteriormente descrito. ${ }^{20}$ Resumidamente, as amostras foram incubadas em 3 ml de uma solução de Hank's (HBSS $®)$, contendo 5,5 mg de proteinase $K \circledR$ e $3 \mathrm{mg}$ de colagenase III por 45 minutos a $37^{\circ} \mathrm{C}$ para a liberação das células. A seguir, foram então, re-suspendidas em $10 \mathrm{ml}$ de HBSS e centrifugadas para o isolamento das células. Alíquotas foram retiradas e a viabilidade celular avaliada, sendo selecionadas para análise somente se apresentassem viabilidade superior a 75 por cento.

A versão alcalina do ensaio do cometa foi realizada de acordo com Ladeira et al. ${ }^{21}$ De forma resumida, $15 \mathrm{ml}$ da suspensão celular previamente obtida foram misturados a agarose low melting point $0.5 \%$ (Promega, Invitogen), postos sobre uma lâmina e cobertos com uma lamínula. Em seguida estas foram imersas em uma solução de lise gelada $(2,5 \mathrm{M} \mathrm{NaCl}$, 100 mM EDTA, 10mM Tris, 1\% SDS, pH 10 com $1 \%$ Triton X-100 e $10 \%$ DMSO) e permaneceram a $4^{\circ} \mathrm{C}$ por 12 horas. Subsequientemente, foram expostas a um tampão alcalino (1 mM EDTA e 300 mM NaOH, $\mathrm{pH} 13,4$ ) por $40 \mathrm{~min}$ a $4^{\circ} \mathrm{C}$. A eletroforese foi realizada neste tampão a $4^{\circ} \mathrm{C}$ por $30 \mathrm{~min}$ a $25 \mathrm{~V}$ e $300 \mathrm{~mA}$. Após a realização da eletroforese, as lâminas foram neutralizadas (0,4 M Tris, $\mathrm{pH} 7,5)$, coradas com $S Y B R$ Safe ${ }^{\circledR}$ e analisadas com um microscópio de fluorescência. Duzentas células foram aleatoriamente selecionadas (100 de cada amostra tecidual) e analisa- das individualmente utilizando-se o software Komet $5.5 \AA$.

Com o auxílio do software Komet 5.5 foi obtido o valor da extensão da cauda do cometa (Tail Moment), sendo seus valores médios determinados. Segundo o manual do fabricante, este é definido como o produto do DNA da cauda e a distância média da migração da cauda. $\mathrm{O}$ tamanho da cauda de cometa reflete a extensão das rupturas das hélices de DNA (estresse oxidativo), e pode ser quantificado por métodos de intensificação de imagem e análise computacional. (Figura 1)

\section{Análise estatística}

Os dados obtidos foram analisados usando o programa estatístico SPSS 13.0Ò . Adotou-se o teste " $t$ " de Student, e as razões de chance e intervalos de confiança de $95 \%$, na comparação entre os valores médios obtidos entre o tecido normal e neoplásico. Foram utilizados testes de tendência (qui-quadrado) e análise de variância (Kruskal-Wallis) para variáveis não paramétricas (tipo histológico, grau histológico, estádio), adotando-se como normal, o valor igual ou inferior a média do dano oxidativo encontrado no tecido normal, e como alterados valores maiores que a média encontrada no tecido normal. Adotou-se $5 \%(\mathrm{p}<0,05)$ como coeficiente para rejeição da hipótese de nulidade.

\section{RESULTADOS}

A Figura 2 mostra os valores médios do Tail Moment (TM) mensurados em 100 células, comparando, em toda a casuística, o tecido normal e o

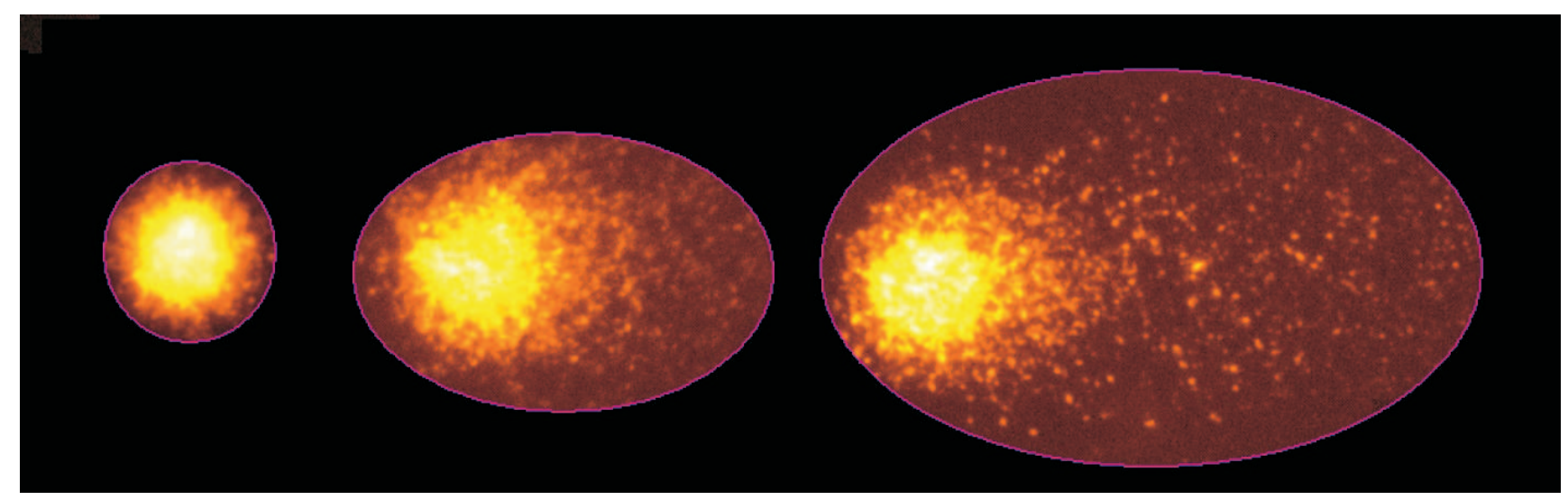

Figura 1 - Avaliação dos níveis de estresse oxidativo (“Tail Moment”), por meio da eletroforese em gel de célula única (ensaio do cometa). $\boldsymbol{A}$-Célula normal; $\boldsymbol{B}$ - Célula com dano oxidativo moderado; $\boldsymbol{C}$-Célula com dano oxidativo grave. 
Rev bras Coloproct Outubro/Dezembro, 2007 neoplásico. Os resultados demonstraram que em todos os doentes ocorria maior intensidade de dano oxidativo no tecido neoplásico quando comparado ao tecido normal. Ao avaliar-se a intensidade de dano oxidativo no tecido normal, encontrou-se valores de TM médios de $1,056 \pm 0,460$, enquanto no tecido neoplásico de 2,532 $\pm 0,945$. A Figura 3 mostra que ao comparar-se o valor médio de TM entre tecidos normal e com câncer, existia intensidade de dano significativamente mais elevada no tecido neoplásico ( $\mathrm{p}=0,00001$; I.C.95\%: $-1,7705$ a-1.1808).

A tabela 2 mostra a relação entre os valores médios de TM no tecido neoplásico e as variáveis analisadas. Não se encontrou relação entre a intensidade de dano oxidativo quando se considerou o gênero dos doentes $(\mathrm{p}=0,32)$. Quando se analisou doentes com idade acima e abaixo dos 70 anos, verificou-se tendência

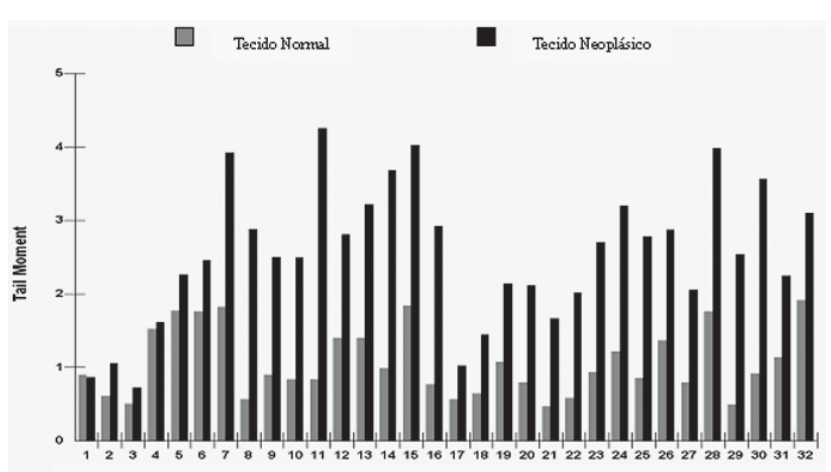

Figura 2 - Níveis de dano oxidativo ao DNA nos tecidos normal e neoplásico na casuística estudada.

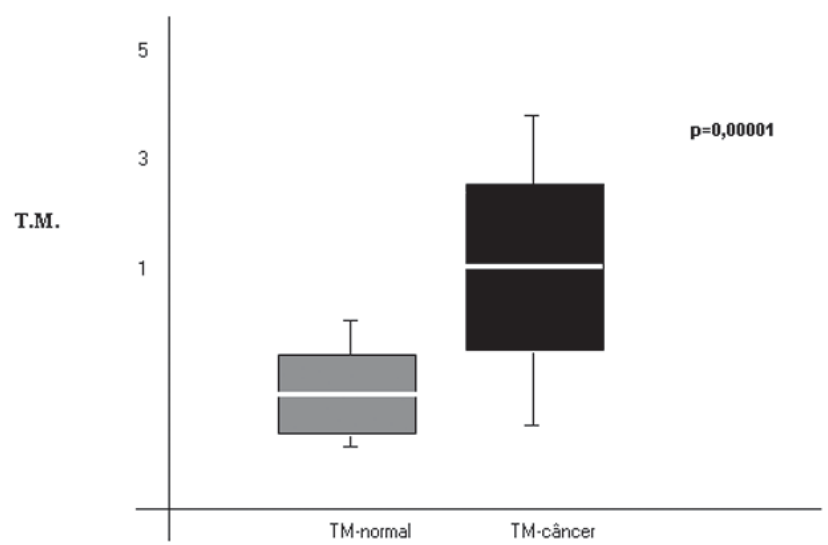

Figura 3 - Gráfico de médias comparando a intensidade de dano oxidativo ao DNA, mensurado pelo Tail Moment, nos tecidos normal e neoplásico. a maior intensidade de dano nos enfermos menores de 70 anos $(\mathrm{p}=0,001)$. Os tumores localizados após a flexura esplênica (cólon distal) apresentaram maior tendência a dano oxidativo que os localizados no cólon proximal $(\mathrm{p}=0,001)$. A média dos valores de TM no tecido neoplásico ao considerarem-se tumores produtores de muco e tumores não produtores, revelou maior tendência a dano oxidativo nos portadores de tumores não mucinosos $(\mathrm{p}=0,001)$. Ao mensurarem-se os valores de TM em relação ao grau histológico constatou-se que a piora do grau histológico encontrava-se relacionada à menor intensidade de dano oxidativo. $(\mathrm{p}=0,03)$. Enfermos que não apresentavam invasão angiolinfática e neural apresentavam maior tendência a dano oxidativo $(\mathrm{p}=0,001$ e $\mathrm{p}=0,007$ respectivamente).

Ao analisar-se a variação dos níveis de dano oxidativo em relação ao estadiamento, foi possível verificar que no tecido neoplásico dos enfermos pertencentes ao estádio A da classificação de Dukes havia, em média, $\mathrm{TM}=3,83 \pm 0,36$; nos do estádio $\mathrm{B}, \mathrm{TM}=$ $2,31 \pm 0,75$ e nos do estádio $\mathrm{C}, \mathrm{TM}=2,48 \pm 1,02(\mathrm{p}=0,04)$. Da mesma forma, quando se comparou o valor médio de TM entre estádios precoces e estádios avançados (III e IV) da classificação TNM (I e II), encontrou-se

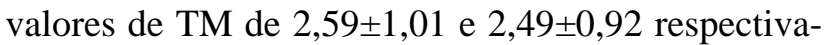
mente $(\mathrm{p}=0,03$; IC $-0,6082$ a 0,8025$)$. Encontrou-se variância decrescente na intensidade de dano oxidativo com a piora do estadiamento $(\mathrm{p}=0,001)$

\section{DISCUSSÃO}

As ERO, também conhecidas como radicais livres de oxigênio, vêm sendo implicadas como fator etiopatogênico de diversas enfermidades que acometem o homem. ${ }^{22}$ No adulto, o estresse oxidativo encontra-se relacionado ao surgimento de enfermidades crônico-degenerativas tais como doenças cardiovasculares e inflamatórias intestinais. ${ }^{17,22} \mathrm{~A}$ avaliação do papel representado pelas ERO nas etapas iniciais da carcinogênese humana vêm mostrando que elas promovem processo inflamatório crônico à mucosa cólica gerando alterações no metabolismo celular normal, em proteínas intracelulares e dano oxidativo ao DNA celular. O estresse oxidativo desencadeado pelas ERO induz instabilidade genômica em diferentes regiões cromossômicas, ocasionando mutações genéticas com conseqüente possibilidade de ganho proliferativo celular descontrolado. ${ }^{22}$ 
Tabela 2 - Valores médios do Tail Moment (TM) nos tecidos normal e neoplásico nas diferentes variáveis estudadas.

\begin{tabular}{|c|c|c|c|}
\hline \multirow[t]{2}{*}{ Variável } & \multicolumn{2}{|c|}{ Dano oxidativo no Câncer } & \multirow[t]{2}{*}{ Valor de $p$} \\
\hline & $\mathbf{N}(\%)$ & Média \pm desvio padrão & \\
\hline \multicolumn{4}{|l|}{ Gênero } \\
\hline Masculino & $15(46,9)$ & $2,69 \pm 0,84$ & 0,32 \\
\hline Feminino & $17(53,1)$ & $2,40 \pm 1,03$ & \\
\hline \multicolumn{4}{|l|}{ Idade } \\
\hline$<70$ anos & $23(71,9)$ & $2,55 \pm 0,83$ & 0,001 \\
\hline$>70$ anos & $9(28,1)$ & $2,47 \pm 1,23$ & \\
\hline \multicolumn{4}{|l|}{ Topografia } \\
\hline Cólon proximal & $4(12,5)$ & $2,32 \pm 0,94$ & 0,001 \\
\hline Cólon distal & $28(87,5)$ & $2,56 \pm 0,96$ & \\
\hline \multicolumn{4}{|l|}{ Grau histológico } \\
\hline Bem & $3 \quad(9,4)$ & $2,68 \pm 0,36$ & \\
\hline Moderadamente & $27(84,4)$ & $2,55 \pm 1,01$ & 0,03 \\
\hline Pouco & $2(6,3)$ & $1,95 \pm 0,41$ & \\
\hline \multicolumn{4}{|l|}{ Tipo histológico } \\
\hline Não mucinoso & $24(75)$ & $2,58 \pm 0,96$ & 0,001 \\
\hline Mucinoso & $8(25)$ & $2,36 \pm 0,92$ & \\
\hline \multicolumn{4}{|l|}{ Classificação TNM } \\
\hline I & $3 \quad(7,4)$ & $2,75 \pm 1,50$ & \\
\hline II & $10(31,3)$ & $2,54 \pm 0,93$ & $0,001^{*}$ \\
\hline III & $10(31,3)$ & $2,68 \pm 0,66$ & \\
\hline IV & $9(28,1)$ & $2,27 \pm 1,14$ & \\
\hline \multicolumn{4}{|c|}{ Classificação Dukes } \\
\hline A & $3 \quad(9,4)$ & $3,83 \pm 0,36$ & \\
\hline $\mathrm{B}$ & $13(40,6)$ & $2,31 \pm 0,75$ & $0,04 *$ \\
\hline $\mathrm{C}$ & $16(50)$ & $2,48 \pm 1,02$ & \\
\hline \multicolumn{4}{|c|}{ Invasão angiolinfática } \\
\hline Presente & $18(50)$ & $2,36 \pm 1,03$ & 0,001 \\
\hline Ausente & $18(50)$ & $2,70 \pm 0,84$ & \\
\hline \multicolumn{4}{|l|}{ Invasão neural } \\
\hline Presente & $13(40,6)$ & $2,32 \pm 0,93$ & 0,007 \\
\hline Ausente & $19(59,4)$ & $2,69 \pm 0,94$ & \\
\hline
\end{tabular}

* Teste de Kruskal-Wallis.

Feanton, em 1894, descreveu pela primeira vez a produção de ERO a partir da dissociação do peróxido de hidrogênio em radicais de hidroxila, em uma reação catalisada pelo íon ferro. ${ }^{23}$ Uma melhor compreensão da ação deletéria das ERO ocorreu após a identificação da enzima superoxidodismutase que apresenta importante ação antioxidante ${ }^{24}$.

As ERO possuem na órbita de seu átomo elétrons não pareados, e são formadas a partir da adição ou perda de elétrons em um átomo neutro. ${ }^{25}$ Normalmente, as ERO são produzidas a partir do metabolismo aeróbico celular, da atividade bacteriana em substratos alimentares no interior da luz intestinal e, principalmente, pela agressão inflamatória à mucosa cólica. ${ }^{17}$ Das ERO, as que apresentam maior potencial agressivo para as células da mucosa intestinal são o superóxido $\left(\mathrm{O}_{2}^{-}\right)$ e a hidroxila $\left(\mathrm{OH}^{-}\right)$, resultantes da dissociação do peróxido de hidrogênio $\left(\mathrm{H}_{2} \mathrm{O}_{2}\right){ }^{17}$ Durante o metabolis- 
mo as células da mucosa intestinal formam ERO pela adição de um elétron ao íon $\mathrm{O}_{2}$, representando a etapa inicial de sua formação a partir da redução do oxigênio molecular. A superoxidodismutase, catalisando a reação, faz com que duas moléculas de $\mathrm{O}_{2}^{-}$reajam com dois átomos de hidrogênio formando o $\mathrm{H}_{2} \mathrm{O}_{2}$. No interior na luz intestinal, por meio da reação de Feanton, catalizada pelo íon $\mathrm{Fe}^{++}, \mathrm{o}_{2} \mathrm{O}_{2}$ forma o radical $\mathrm{OH}^{-}$, a mais reativa entre todas as ERO. ${ }^{24}$

As ERO são eletrofílicas, com atividade altamente reativa, atacando substâncias com alta densidade de elétrons tais como as bases nitrogenadas que formam os ácidos nucléicos que compõe a molécula de DNA. ${ }^{26}$ Dentre os mecanismos mais bem estudados de dano oxidativo ao DNA encontra-se a oxidação da base nitrogenada guanina. ${ }^{27}$ Nesta reação existe a incorporação de um radical $\mathrm{OH}^{-}$no carbono 8 da molécula da guanina, formando a 8-hidroxi-guanina (8OHdG) (Figura 4). ${ }^{27}$

Durante o processo de duplicação do DNA, a guanina normalmente pareia-se com a citosina (G-C). Contudo, durante o processo de duplicação do DNA, caso ocorra a formação da 8-OHdG, por um fenômeno conhecido como transversão, a guanina oxidada pareiase, de forma errônea, com uma molécula de timina (GC (B-T). Na eventualidade de não haver correção, por meio das proteínas de reparo do DNA, no local onde ocorreu a inserção da 8-OHdG, poderá haver transcrição equivocada, com a conseqüente formação de uma proteína defeituosa. Caso esta proteína mutante se encontre relacionada aos mecanismos de controle do ciclo celular, a célula poderá ganhar autonomia proliferativa, formando um clone de células mutantes com características semelhantes. Este desequilíbrio do ciclo celular, com favorecimento da proliferação em detrimento da apoptose, poderia se constituir na explicação molecular para o início de formação dos pólipos. Com o progredir da agressão oxidativa ocorrem sucessivas mutações em genes supressores de tumor ou oncogenes (APC, k-ras, DCC, p53) promovendo o crescimento celular anárquico (displasia tecidual) culminando com o aparecimento do CCR. À medida que o estresse oxidativo persiste as células neoplásicas, em virtude do acúmulo de mutações em genes que controlam o ciclo celular, perdem a capacidade de apoptose, tornando-se dessa forma menos sensíveis a novas agressões oxidativas. ${ }^{28}$

A quantificação da $8-\mathrm{OHdG}$ tem sido usada como método para mensurar os níveis de dano oxidativo ao DNA. Durante os últimos anos diferentes métodos bioquímicos e analíticos foram desenvolvidos com o objetivo de avaliar a presença do estresse oxidativo nos tecidos humanos. A quantificação do estresse oxidativo em bases do DNA apresenta grande interesse, por permitir a melhor compreensão do seu papel nas diferentes etapas do processo de carcinogênese. ${ }^{18}$ Habitualmente, a quantificação do dano oxidativo nuclear envolve técnicas de extração do DNA dos tecidos e análise por cromatografia a gás ou técnicas imunohistoquímicas. Geralmente estas técnicas não podem ser aplicadas para pequenos fragmentos de tecidos obtidos por biópsia em virtude dos limites relacionados à sua metodologia. Por esta razão, encontramse poucos estudos que analisaram comparativamente, a intensidade de estresse oxidativo nas diversas etapas evolutivas do processo de carcinogênese colorretal. ${ }^{18}$
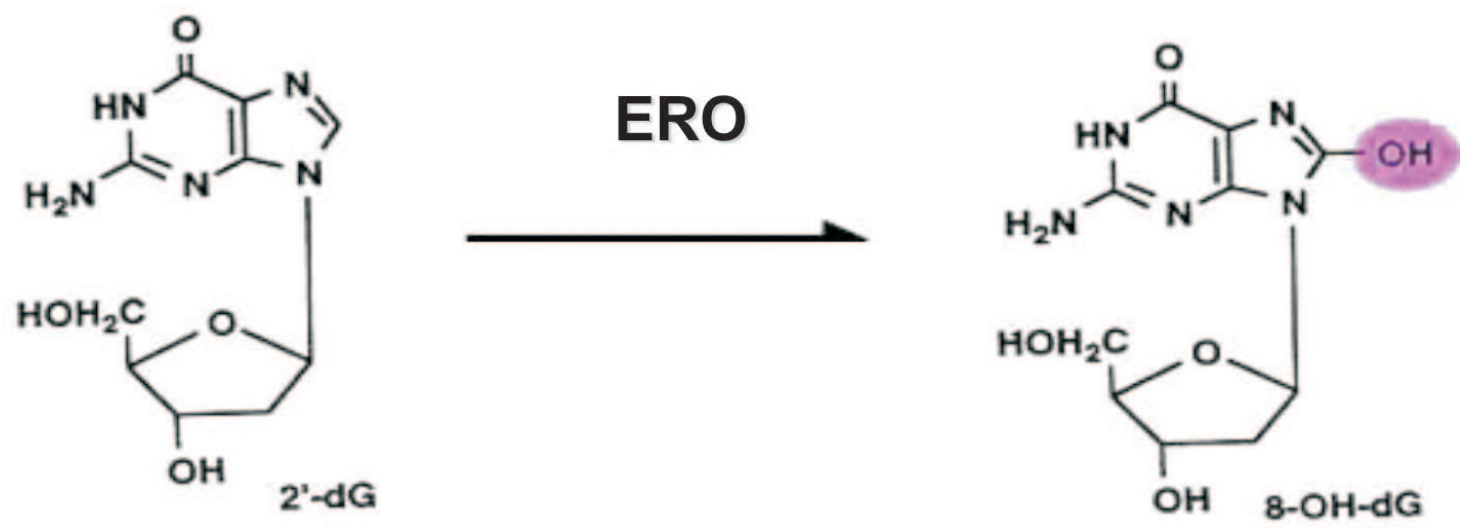

Figura 4 - Formação de 8OHdG pelas espécies livres de oxigênio a partir da guanina (2'-dG). 
A possibilidade de mensurar os níveis de dano oxidativo em pequenos fragmentos de tecido da mucosa cólica em diversos estágios da carcinogênese, poderia contribuir para melhor compreensão do papel representado pelas ERO em todas as etapas do desenvolvimento do CCR.

Singh et al. desenvolveram, em 1988, uma técnica simples, capaz de detectar os níveis de danos oxidativos ao DNA em uma célula isolada. ${ }^{29}$ Esta técnica foi inicialmente chamada de "eletroforese em gel de célula única" sendo hoje popularmente conhecida como "ensaio do cometa". ${ }^{29}$ Neste contexto, o ensaio do cometa permite de maneira simples e precisa a quantificação dos níveis de dano oxidativo ao DNA de pequenas quantidades de tecido obtidos a partir de biópsias. ${ }^{30}$ Talvez uma de suas maiores vantagens seja possibilitar a quantificação do dano ao DNA de uma única célula, o que permite a interpretação individualizada do estresse oxidativo à mucosa cólica nos diversos estágios da carcinogênese. ${ }^{30} \mathrm{~A}$ possibilidade de quantificar o dano oxidativo nos vários estágios da carcinogênese permitiria ainda, a avaliação da eficácia de diversos agentes antioxidantes, tais como os antiinflamatórios inibidores da COX-2, na proteção do DNA contra mutações ocasionadas pelo estresse oxidativo.

A mensuração da intensidade de dano oxidativo é essencial para o melhor entendimento dos mecanismos etiopatogênicos do estresse oxidativo e seus efeitos moleculares. A agressão inicial à mucosa cólica normal surge a partir de um processo inflamatório formador de ERO que desencadeia mutações progressivas em genes reguladores do ciclo celular. A possibilidade de quantificar os níveis de dano oxidativo nas células submetidas a diferentes graus de inflamação torna-se uma estratégia interessante para avaliar a responsabilidade das ERO nas várias etapas da carcinogênese. A relação entre estresse oxidativo e inflamação já foi anteriormente descrita, quando se verificou aumento na intensidade de dano oxidativo ao DNA quanto mais duradouro e intenso fosse o processo inflamatório, determinando o aparecimento de lesões displásicas possivelmente relacionadas ao surgimento do câncer. ${ }^{31}$ Estudos experimentais demonstraram que em camundongos silenciados para o gene Il-10, aproximadamente $60 \%$ deles desenvolveram tumores no cólon proximal após um período inicial de intenso processo inflamatório na mucosa cólica. ${ }^{32}$ Da mesma forma, $30 \%$ dos camundongos silenciados simultaneamente para os genes Il-2 e b2 microglobulina desenvolveram adenocarcinoma no cólon, após longo período de exuberante processo inflamatório, com índices de mutações nos genes APC e p53 de $100 \%$ e $60 \%$ respectivamente. ${ }^{33}$ Como a mutação da proteína APC é considerada um evento inicial no processo de carcinogênese colorretal, determinando um descontrole da proliferação celular, é possível que a acentuada formação de ERO, promovendo agressão inflamatória crônica, possa estar relacionada aos altos índices de mutação encontradas neste gene. Estudos comparando o tecido inflamatório e o neoplásico em portadores de colite ulcerativa, mostraram que o espectro de mutações do gene p53 é dominado pelo fenômeno de transição de bases do DNA provavelmente desencadeado pela formação de ERO. ${ }^{34}$ Recentemente, Oliva et al demonstraram níveis duas vezes mais elevados de 8OHdG no tecido neoplásico de portadores de CCR quando compararam com o tecido normal..$^{35}$ Constataram ainda, avaliando a expressão de vários genes relacionados à carcinogenese colorretal, que em $71 \%$ dos doentes que apresentaram altos níveis de estresse oxidativo, o gene p53 apresentava elevados índices de mutação destacando a importância da relação entre estresse oxidativo e mutações do gene p53. ${ }^{35}$ Dessa maneira é possível que a ação das ERO sob o gene p53 também determinem mutações provocando alterações no mecanismo de controle da apoptose celular programada.

Os resultados do presente estudo encontramse de acordo com os achados da literatura, quando se observou no tecido neoplásico níveis de dano oxidativo ao DNA significativamente maiores quando comparados ao tecido normal. ${ }^{36}$ Contudo, deve-se ressaltar, que no tecido normal já era possível identificar algum grau de estresse oxidativo o que reforça a importância das ERO nas etapas iniciais da agressão tecidual. É provável que nestes tecidos, eventuais erros de pareamento provocados pela formação de $8-\mathrm{OHdG}$ tenham sido reconhecidos pela proteína $\mathrm{p} 53$ normal e corrigidos por meio de proteínas de reparo, impedindo a mutação de genes responsáveis pelo controle da proliferação celular. ${ }^{18}$ Quando o dano oxidativo excede a capacidade de correção do DNA pelas proteínas de reparo, a proteína p53 normal reconhece o dano induzindo a apoptose celular e impedindo a formação de um clone de células mutantes. Já se demonstrou a importante relação existente entre deficiências no sistema de reparo e aumento nos níveis de dano oxidativo ao DNA em portadores 
de CCR. ${ }^{37}$ Atualmente, estamos analisando pela técnica da PCR em tempo real (RT-PCR), no mesmo grupo de doentes da presente casuística, a expressão de genes relacionados ao sistema de reparo e apoptose (hMLH1, hMSH2, BCL2, BAX e p53) nos tecidos normais e neoplásicos com o objetivo de relacioná-los aos níveis de estresse oxidativo.

Quando se relacionou a intensidade de dano oxidativo com o gênero, de modo diferente da literatura, não foi possível encontrar-se diferenças significantes $(\mathrm{p}=0,32) .{ }^{18}$ Ao avaliar-se a intensidade de dano em relação à localização da neoplasia verificou-se que tumores localizados após a flexura esplênica apresentavam maior tendência a dano quando comparados aos localizados antes da flexura esplênica (TM 2,56 $\pm 0,96$ e TM 2,32 $\pm 0,94$, respectivamente; $p=0,001)$. É possível que estes resultados encontrem-se relacionados às diferentes vias de carcinogênese, quando se consideram tumores localizados antes e após a flexura esplênica. É sabido que o processo de carcinogênese dos tumores localizados no cólon distal encontra-se relacionado à sequiência adenoma-carcinoma, onde a mutação do gene p53 é um evento comum. Tumores localizados no cólon proximal são considerados câncer "de novo", por desenvolverem-se a partir da mucosa cólica habitualmente desprovida de pólipos estando geralmente associados a mutações em proteínas de reparo. ${ }^{38}$ Estudos anteriores demonstraram que tumores localizados no cólon distal, apresentam maior possibilidade de mutações da proteína p53 quando comparados aos do cólon proximal. ${ }^{38}$ Análises realizadas em tecidos submetidos a agentes indutores de estresse oxidativo, vêm confirmando a relação existente entre níveis aumentados de 8-OHdG e mutações da proteína p53. ${ }^{39}$ Como existe relação entre estresse oxidativo e mutação do gene p53, é possível que tumores de localização distal apresentem maior intensidade de dano pela impossibilidade da sua correta identificação por cursarem com maiores índices de mutações no gene p53.

Quando se considerou o tipo histológico da neoplasia verificou-se maior intensidade de estresse oxidativo nos tumores não produtores de muco. Estes achados talvez se encontrem relacionados ao pior grau histológico, habitualmente encontrado nos tumores produtores de muco. Embora não existissem diferenças significantes quando se comparou o valor médio de dano oxidativo nos diferentes graus histológicos, verificouse que tumores bem diferenciados apresentavam tendência a danos mais elevados que os moderadamente e pouco diferenciados ( $\mathrm{p}=0,03)$. É possível que a célula neoplásica indiferenciada, acumule um número tão grande de mutações que esteja menos susceptível a novas agressões oxidativas. ${ }^{28}$ Os resultados iniciais de um estudo recém iniciado onde comparamos os níveis de estresse oxidativo no tecido normal em pólipos e no CCR, vem demonstrando maior intensidade de dano nos pólipos quando comparado ao tecido normal e ao neoplásico. É possível que nas etapas iniciais da formação do pólipo, onde a agressão inflamatória inicial é o evento predominante, exista maior formação de ERO traduzida pelos valores mais elevados de dano oxidativo. Nessa fase, as proteínas de reparo exercendo seu papel de correção do DNA danificado pelo estresse oxidativo, ainda conseguem reparar o DNA evitando o surgimento das mutações relacionadas à formação da célula neoplásica. No tecido neoplásico, onde o processo inflamatório já não é tão exuberante, talvez ocorra menor intensidade de dano oxidativo, traduzido pelos menores valores de TM quando comparado ao tecido adenomatoso. Estudos vêm mostrando que, as células neoplásicas como já possuem inativação ou deleção de genes supressores de tumores e/ou ativação de oncogenes que determinam autonomia proliferativa, se tornam muito menos dependentes da agressão oxidativa externa quando comparadas às células normais. ${ }^{28} \mathrm{Re}$ sultados semelhantes foram encontrados por estudos que compararam os níveis de dano oxidativo ao DNA em portadores de gastrite e neoplasia gástrica associada ou não à presença da Helicobacter pylori. ${ }^{40}$

Ao analisar-se a intensidade do dano oxidativo segundo o estadiamento TNM e a classificação original de Dukes, verificou-se que os doentes pertencentes aos estádios precoces das classificações apresentavam valores médios mais elevados que os classificados em estádios mais avançados. É possível que tumores menos avançados em virtude do menor número de mutações em genes relacionados à capacidade de adesão celular e angiogênese ainda sejam passíveis de sofrerem ainda agressão oxidativa. Nos tumores com estádios mais avançados as mutações existentes já conferem autonomia proliferativa, imortalidade celular, suprimento sangüíneo adequado e capacidade de migração celular, condições necessárias para a disseminação da doença independentemente da necessidade de novos danos ao DNA.

O presente estudo confirmou a validade da eletroforese em gel de célula única na determinação dos níveis de estresse oxidativo ao DNA em doentes 
Rev bras Coloproct Outubro/Dezembro, 2007
Avaliação do Dano Oxidativo ao DNA de Células Normais e Neoplásicas da Mucosa Cólica de Doentes com Câncer Colorretal Marcelo Lima Ribeiro e Cols. com CCR. A quantificação do estresse oxidativo foi realizada a partir de pequenas amostras de tecido que poderiam ter sido facilmente obtidas em exames endoscópicos. Portanto, trata-se de metodologia exequiível que permitiria a mensuração do dano oxidativo ao longo de todas as etapas do processo de desenvolvimento do $\mathrm{CCR}$.

Estudos com maior número de doentes, correlacionando o estresse oxidativo a mutações em cada um dos genes envolvidos na formação do CCR ainda são necessários para avaliar de forma mais precisa o papel desempenhado pelas ERO em cada uma das etapas da carcinogênese. Com o advento de técnicas de microarray e tissue microarray que possibilitam o estudo simultâneo da expressão de um grande número de genes ou das proteínas mutantes por eles formadas, associadas a métodos de quantificação do estresse oxidativo, tais como o ensaio do cometa, será possível compreender melhor o papel desempenhado pelas ERO na formação do CCR. A avaliação dos níveis de dano oxidativo, nas diferentes etapas da carcinogênese colorretal, apresenta grande interesse por permitir a avaliação da eficácia de substâncias antioxidantes, que poderiam ser empregadas como medidas preventivas da agressão oxidativa inicial à mucosa cólica.

\section{CONCLUSÃO}

Os resultados encontrados no presente estudo permitem concluir que as células da mucosa cólica normal, em portadores de CCR, já apresentam danos oxidativos ao DNA, embora significativamente menores que as células do tecido neoplásico.

\begin{abstract}
Oxidative stress on mucosal cells of the colon, resulting from the action of free radicals present in the intestinal lumen, represents one of the initial phenomena in colorectal carcinogenesis, because it may induce gene mutations relating to cell cycle control. Quantification of the oxidative damage to the DNA in colorectal cancer patients has been little studied so far. Objective: To measure the levels of oxidative damage to the DNA in cells isolated from the colon mucosa in colorectal patients, and to compare normal and neoplastic tissues and make correlations with anatomopathological variables. Method: Thirty colorectal adenocarcinoma patients (eighteen women) of mean age $60.6 \pm 15.5$ years who consecutively underwent operations performed by the same surgical team between 2005 and 2006 were studied. The oxidative damage to the DNA was evaluated by means of the alkaline version of the comet assay (single-cell gel electrophoresis), from fragments of normal and neoplastic colon tissue that were obtained immediately after removal of the surgical specimen. The extent of breakages of the DNA helices was assessed using an image intensification method, on 200 randomly chosen cells (100 from each tissue sample), by means of the Komet 5.5 program. The Tail Moment (T.M) measured in each cell quantitatively represented the extent of the oxidative damage to the DNA. The statistical analysis on the variables considered was performed by means of the Student $t$, chi-squared and Kruskal-Wallis tests, with a significance level of $5 \%(p<0.05)$. Results: It was found that, for all the patients studied, the cells obtained from the neoplastic tissue presented oxidative damage to the DNA that was greater than in the cells from normal tissue. The cells isolated from the neoplastic mucosal tissue of the colon presented extension of DNA strand breakage significantly greater $($ T.M. $=2.532 \pm 0.945)$ than did the cells isolated from normal tissue $($ T.M. $=1.056 \pm 0.460)(p=0.00001 ;$ C.I. $95 \%:-1.7705$ to -1.1808). It was found that the patients at earlier stages of the Dukes and TNM classifications presented higher levels of oxidative damage than did those at more advanced stages ( $p=0.04$ and $p=0.001$, respectively). Conclusions: The cells obtained from normal tissue of colorectal cancer patients presented signs of oxidative damage to the cell DNA, although at significant lower levels than in the neoplastic cells.
\end{abstract}

Key words: Oxidative stress. Oxidants. Comet assay. Colorectal neoplasia.

\section{REFERÊNCIAS}

1. Boring CC, Squires TS, Tong T. Cancer statistics 1993. CA Cancer J Clin. 1993; 43:7-26.

2. Glei M, Latunde-Dada GO, Klinder A, Becker TW, Hermann $\mathrm{U}$, Voigt K, et al. Iron-overload induces oxidative DNA damage in the human colon carcinoma cell line HT29 clone 19A. Mutation Research.2002; 519:151-61.
3. Garfinkel L, Mushinski M. U.S. cancer incidence, mortality and survival: 1973-1996. Stat Bull Metrop Insur Co. 1999; 80:23-32.

4. Instituto Nacional do Câncer. Estimativas da incidência e mortalidade por câncer no Brasil 2003. Disponível em <http:// www.inca.gov.br.> Acesso em: 9 jul.2004.

5. Neves FJ, Mattos IE, Koifman RJ. Mortalidade por câncer de cólon e reto nas capitais brasileiras no período 1980-1997. Arq Gastroenterol. 2005; 42:63-70. 
6. Malheiros APR, Teixeira MG, Habr-Gama A, Alcântara PSM. Resultados do tratamento cirúrgico do câncer colo-retal em doentes de idade até 64 anos e de 65 anos ou mais. Rev bras Coloproct 2005; 25:128-36.

7. Fearon ER, Vogelstein B. A genetic model for colorectal tumorigenesis. Cell.1990; 61:759-67.

8. Fleisher AS, Esteller M, Harpaz N. Microsatellite instability in inflammatory bowel disease-associated neoplastic lesions is associated with hypermethylation and diminished expression of the DNA mismatch repair gene, hMLH1. Cancer Res.2000; 60, 4864-68.

9. Wheeler JMD, Kim HC, Efstathiou JA, Ilyas M, McMortensen NJ, Bodmer WF. Hypermethylation of the promotor region of the E-cadherin gene (CDH1) in sporadic and ulcerative colitis associated colorectal cancer. Gut.2001;48: 367-371.

10. Giovannucci E, Willet WC. Dietary factors and risk of colon cancer. Ann Med.1994; 26:443-52.

11. Binghan SA. Epidemiology and mechanisms relating diet to risk of colorectal cancer. Nut Res Rev. 1996; 9:197-239.

12. Riboli E. The European prospective investigation into cancer and nutrition (EPIC): plans and progress. J Nutr.2001; 131:170S-175S.

13. Norat T, Bingham S, Ferrari P, Slimani N, Jenab M, Mazuir $\mathrm{M}$, et al. Meat, fish, and colorectal cancer risk: the European prospective investigation into cancer and nutrition. J Nat Cancer Inst. 2005; 97:906-16.

14. Imlay J, Chin SM, Linn S. Toxic DNA damage by hydrogen peroxid through the Fenton reaction in vivo and in vitro. Science. 1988; 240:640-2.

15. Hata Y, Kawabe T, Hiraishi H, Ota S, Terano A, Ivey KJ. Hydrogen peroxide-mediated cytotoxicity to cultured colonic epithelial cells. Life Sci.1997; 60:2221-30.

16. Potter JD. Colorectal cancer. Molecules and populations. J Nat Cancer Inst.1999; 91:105-16.

17. Seril DN, Liao J, Yang GY, Yang CS. Oxidative stress and ulcerative colitis-associated carcinogenesis: studies in humans and animals models. Carcinogenesis. 2003; 24:353-62.

18. Pool-Zobel BL, Abrahamse SL, Collins AR, Kark W, Gugler R, Oberreuther D, Siegel EG, et al.. Analysis of DNA strand breakes, oxidized bases, and glutathione S-tranferase P1 in human colon cellsfrom biopsies. Cancer Epidemiol Biomarkers Prevention.1999;8:609-614.

19. Associação Médica Brasileira - Projeto Diretrizes. Diagnóstico, Estadiamento e Tratamento Cirúrgico e Multidisciplinar do Câncer Colorretal.[on line].2001. [Acesso em 24 de mai 2007] 1:1-12. Disponível em URL: < http:// www.projetodiretrizes.org.br/projeto_diretrizes/020.pdf >.

20. Pool-Zobel BL, Lotzmann N, Knoll M, Kuchenmeister F, Lambertz R, Leucht U, et al.. Detection of genotoxic effects in human gastric and nasal mucosa cells isolated from biopsy samples. Environ Mol Mutagen.1994; $24: 23-45$
21. Ladeira MS, Rodrigues MA, Salvadori DM, Queiroz DM, Freire-Maia DV. DNA damage in patients infected by Helicobacter pylori. Cancer Epidemiol Biomarkers Prev.2004;13:631-7.

22. Ames B, Shigenaga M, Hagen T. Oxidants, antioxidants, and the degenerative diseases of aging. Proc. Natl.Acad. Sci. 1993; 90, 7915-7922.

23. Hata Y, Kawabe T, Hiraishi H, Ota S, Terano A, Ivey KJ Hydrogen peroxide-mediated cytotoxicity to cultured colonic epithelial cells. Life Sciences.1997;60: 2221-2230.

24. McCord JM, Fridovich I. Superoxide dismutase the first twenty years (1968-1988). Free Radic Biol Med.1988;5:3639.

25. Pilcher J. Free radicals. Neonatal Netw.2002;21:33-7. Inflamm Bowel Dis. 2004 Jan;10(1):23-7.

26. Battacharya PK, Barton JK. Influence of intervening mismatches on long range guanine oxidation in DNA duplexes. J Am Chem Soc.2001;123:8649-56.

27. Kasai H, Nishimura S. Hydroxylation of the C-8 position of deoxyguanosine by reducing agents in the presence of oxygen. Nucleic Acids Symp Ser. 1983;12:165-7.

28. Toyokuni S, Okamoto K, Yodoi J, Hiai H. Persistent oxidative stress in cancer. FEBS Lett.1995.358:1-3.

29. Singh NP, McCoy NT, Tice RR, Schneider EL. A simple technique for quantitation of low levels of DNA damage in individual cells. Exp Cell Res. 1988;175:184-91.

30. Pool-Zobel BL, Abrahamse SL, Collins AR, Kark W, Gugler R, Oberreuther D, et al.. Analysis of DNA strand breaks, oxidized bases, and glutathione S-transferase P1 in human colon cells from biopsies. Cancer Epidemiol Biomarkers Prev. 1999;8:609-14.

31. D'Inca R, Cardin R, Benazzato L, Angriman I, Martines D, Sturniolo GC. Oxidative DNA damage in the mucosa of ulcerative colitis increases with disease duration and dysplasia. Inflamm Bowel Dis. 2004;10:23-7.

32. Berg DJ, Davidson N, Kuhn R, Muller W, Menon S, Holland $\mathrm{G}$, et al. Enterocolitis and colon cancer in interleukin-10deficient mice are associated with aberrant cytokine production and CD4 (+) TH1-like responses. J. Clin. Invest.1996; 98:1010-20.

33. Sohn KJ, Shah SA, Reid S, Choi M, Carrier J, Comiskey M, et al. Molecular genetics of ulcerative colitisassociated colon cancer in the interleukin 2- and beta(2)-microglobulindeficient mouse. Cancer Res.2001; 61:6912-17.

34. Hussain SP, Harris CC. Molecular epidemiology of human cancer: contribution of mutation spectra studies of tumor suppressor genes. Cancer Res.1998; 58: 4023-37.

35. Oliva MR, Ripoll F, Muniz P, Iradi A, Trullenque R, Valls V, et al.. Genetic alterations and oxidative metabolism in sporadic colorectal tumors from a Spanish community. Mol Carcinog.1997;18:232-43.

36. Kondo S, Toyokuni S, Iwasa Y, Tanaka T, Ondera H, Hiai H, et al.. Persistent oxidative stress in human colorectal carcino- 
ma, but not in adenoma. Free Radic Biol Med. 1999;27:40110 .

37. Blasi MF, Ventura I, Aquilina G, Degan P, Bertario L, Bassi C, et al. A human cell-based assay to evaluate the effects of alterations in the MLH1 mismatch repair gene. Cancer Res. 2006;66:9036-44.

38. Martinez CAR, Priolli DG, Piovesan H, Cardinalli IA, Portes AV, Pereira JÁ, Margarido NF. Diferenças na expressão da proteína p53 segundo a localização do câncer colorretal: Estudo de 100 casos. Rev bras Coloproct.2006;26 (supl. 1):96-7.

39. Perra MT, Maxia C, Corbu A, Minerba L, Demurtas P, Colombari R, Murtas D, et al. Oxidative stress in pterygium: relationship between $\mathrm{p} 53$ and 8-hydroxydeoxyguanosine.Mol Vis.2006;30:1136-42.
40. Ladeira MS, Bueno RC, Dos Santos BF, Pinto CL, Prado RP, Silveira MG, Rodrigues MA, Bartchewsky W Jr, Pedrazzoli J Jr, Ribeiro ML, Salvadori DM. Relationship among Oxidative DNA Damage, Gastric Mucosal Density and the Relevance of cagA, vacA and iceA Genotypes of Helicobacter pylori. Dig Dis Sci. 2007; [Epub ahead of print].

\section{Endereço para correspondência:}

\section{CARLOS AUGUSTO REAL MARTINEZ}

Rua José Raposo de Medeiros, 474 apto. 62.

Bragança Paulista - São Paulo

12914-450

Tel.: (11) 4438-9203

E-mail: caomartinez@uol.com.br 